\title{
Smart City Architecture: Vision and Challenges
}

\author{
Narmeen Zakaria Bawany \\ Systems Research Laboratory, \\ FAST-National University of Computer and Emerging \\ Sciences \\ Karachi, Pakistan
}

\author{
Jawwad A. Shamsi \\ Systems Research Laboratory, \\ FAST-National University of Computer and Emerging \\ Sciences \\ Karachi, Pakistan
}

\begin{abstract}
The concept of smart city was born to provide improved quality of life to citizens. The key idea is to integrate information system services of each domain, such as health, education, transportation, power grid etc., of the city to provide public services to citizens efficiently and ubiquitously. These expectations induce massive challenges and requirements. This research is aimed to highlight key ICT (Information and Communication Technology) challenges related to adaptation of smart city. Realizing the significance of effective data collection, storage, retrieval, and efficient network resource provisioning, the research proposes a high level architecture for smart city. The proposed framework is based on a hierarchical model of data storage and defines how different stakeholders will be communicating and offering services to citizens. The architecture facilitates step by step implementation towards a smart city, integrating services, as they are developed in a timely manner.
\end{abstract}

Keywords-Smart city; Data management; urban technology; socio-technical systems; smart city architecture

\section{INTRODUCTION}

Smart city brings enormous opportunities and exciting challenges. In general, a metropolitan area can be considered as smart when city operations and services such as healthcare, education, transport, parking, and electricity grid are supported through ICT infrastructure in order to facilitate efficiency and ease of operation. Some valid examples of such services would be looking for a job, applying for a driver's license, buying of car and property, change of the address, request for a passport, start of a new business, reporting of a crime, declaration of income taxes, seeking health services, and so on. All such services require execution of several services under an orchestrated coordination. The smart city design must be citizen-centric. Despite the complexity of the city's systems, the architecture must bring benefits to the people regardless of their ICT abilities.

The primary goals of the smart city include, offering digital means for supporting social needs in all daily transactions, to adapt the citizens to the notion of the information society and to collect information from the public departments and citizens in order to support sustainable growth of the city. Above all, development of smart city will give way to implementation of a citizen-centered public administration, where corruption phenomena and timeconsuming bureaucratic procedures are eliminated [1],[2].

Smart city has been actively studied and researchers have come up with different definitions, frameworks, and implementations of smart city [3],[4],[5],[6],[7]. The key objective of almost all the research is to present a strategy to mitigate the problems generated by the urban population growth by using information and communication technology. Cities and megacities generate new kinds of problems. Difficulty in waste management, scarcity of resources, air pollution, human health concerns, traffic congestions, electricity generation, distribution, and billing, and inadequate, deteriorating, and aging infrastructures are among the more basic technical, physical, and material problems [8][9][10]. Many cities have taken the initiative in this direction and more work is in progress. [11],[12],[3],[13],[14]. In this above context, a smart city system can be considered as a massive information system comprising of several smaller but efficient subsystems that may be connected with each other. Each of these subsystems require efficient and enhanced capabilities to handle components for data storage, information retrieval, networking, and communication.

There are numerous challenges in realization of a city that monitors and integrates all of the city infrastructure and services to leverage the collective intelligence. From technical infrastructure, that needs to be put in place, to adaption of system by citizens various technical and non-technical obstacles are to be dealt with. For example, smart transport management system has immense potential to improve road safety and reduce traffic congestions. However, the system may require new types of networks such as Vehicular AdHoc network (VANETs) to facilitate the communication between vehicles. Huge infrastructure will be needed across the city to make intelligent traffic management possible. Similarly, there are stringent requirements of security and privacy on data, which will be collected and disseminated.

The purpose of this paper is to highlight key challenges related to information system management in smart cities and to propose a model to address these challenges. For instance, for a smart city, networking infrastructure should support extensive monitoring and comprehensive data collection. Further, efficient means of data storage and retrieval are also needed. A critical requirement for smart city is to make the relevant data available for applications in order to materialize the idea of smart city. This induces additional requirements of availability, scalability, security, and privacy. Considering the massive size of cities and increasing trends of urbanization, severity of these challenges and requirements are extensive. Considering these challenges, this paper presents a high-level architecture for smart city. Our proposed model focuses on efficient storage and distribution of data in order to facilitate different operations of smart city. 
The model consists of hierarchical storage with distributed zones of data, which allows rapid and autonomous processing of data and permits instant decision making. The hierarchal model is also beneficial in providing data redundancy and reduces network latency. The hierarchal model also compliments service-oriented architecture, which restricts access to data and enhances and privacy. The zonal model provides access to data for development of third party applications which may subsequently lead to smart city app store.

The main contributions of this paper are follows:

- Accentuate key challenges in smart city implementation

- Propose a zone-based architecture for data storage and management in order to address key challenges for smart city information system management.

- Emphasize an open data model for smart city that gives way to third party application development.

\section{RELATED WORK}

Mahmoud et al. [15] proposes centralized operational platform for smart city. He proposes pyramid like conceptual development pyramid with smart infrastructure at the bottom, followed by smart database resources, smart building management, smart interface and smart city at the top. The primary background of this research is to provide a single management system for the collective processing and management across multiple sub-systems, applications and controllers. The GIS automation platform is used for administering and maintaining the assets. Cisco, IBM, HP, and other global information and communications technology (ICT) players have launched their own smart planet and smart city initiatives. The smart city market is estimated to be hundreds of billions of dollars by 2020, with annual spending reaching nearly $\$ 16$ billion [16]. Harrison et al's[5], proposes a three layer architecture for smart city, an instrumented layer, interconnected layer and intelligent layer. Instrumentation enables the capture and integration of live real-world data through the use of sensors. The activities found at this level can measure water quality, collect electrical meter readings for a grid, or provide building measurements to determine its energy usage. Interconnected layer also called middle layer integrates the data collected at instrumented layer and maps various inputs into events of interest. This layer incorporates the data into an enterprise computing platform and the communication of such information among the various city services. The intelligent layer processes relevant city data in a broader context to identify city-relevant events that need to be analyzed or acted upon. A service-oriented architecture (SOA)-based model, along with existing applications and management systems, is used to transform data and perform analysis. Motivated by the limitations of current internet architecture highlighted by Future Internet Assembly Piro et al.[17] proposes the smart city platform based on the emerging Named Data Networking (NDN) network paradigm. The service platform proposed in this work is built on two levels: the service layer and the technology layer, both interacting through a NDN interface. For service provisioning, three consecutive phases are conceived (1) the Discovering phase, (2) the Security Initialization phase, and (3) the Service Usage phase. Dirks and Keeling [19] suggested that cities are based on six core systems comprising different infrastructures related to their key functions that is people, business, transport, communication, water and energy. Peoples system includes public safety, health and education while businesssystem refers to the environment that businesses face in terms of policy and regulation. All six systems together forms systems of systems. Anthopoulos and Tsoukalas[18] proposes a multi-tier generic architecture which can describe all the types of attributes needed to support the smart city context. This generic architecture contains the four layers. User Layer that consists of all e-service end-users and stakeholders of a smart city, Service Layer incorporates all the particular e-services being offered by the smart city, Infrastructure Layer contains network, information systems and other facilities, which contribute to e-service deployment and Information Layer presents all the information, which is required, produced and collected in the smart city.Doran et al.[19] has developed a smart city model describing the three main components that the smart city system aims to Integrate economic component, environment component and social component. Economic component includes public administration and economic actors. It covers governance models, urban regeneration, open data, big data, bandwidth, mobility, cloud computing, security, business intelligence, etc. Environmental component includes resources and managerial infrastructures. It covers water, air, energy and waste management, public and alternative transportation, geographical information, green buildings, green spaces, smart growth, climate change measurement, etc. Social component includes citizens. It covers community life, urban mediation, participatory democracy, social innovation, human-scale cities, civic participation, proximity services, etc.

\section{KEY CHALLENGES}

Smart city being a gigantic information system, comprising sub information systems, bring enormous challenges. Smart city initiatives are fundamentally based on ICT. The latest developments in cloud computing, Internet of Things, open data, semantic web, and future internettechnologies will be leading technologies to enable smart city development. These technologies can altogether provide infrastructure, applications and turn-key solutions for offering various services. ICT has immense potential to enhance the management and functioning of a city which in turn will benefit citizens. However, all these technologies have their inherent challenges and limitations. Combining all these technologies to form a complex system, like smart city, will magnify the amplitude of many long-standing challenges.

\section{A. IT Infrastructure}

The development of ICT infrastructure, from communication channels to sensors and actuators in physical space remains a huge barrier in taking a smart city initiative. Lack of infrastructure is a significant barrier in achieving smart city objectives [1][20][21][22][23][24]. Reliable, scalable and high speed network connectivity and infrastructure is a key foundation for integrating information 
systems across city. This infrastructure has to be in place before smart city services are offered to stake holders. Consequently, the adequate reliable IT infrastructure which tends to be scalable is a critical challenge for the implementation of smart city.

\section{B. Security and privacy}

As the trend move towards smart city, and different gadgets becomes integrated within everyday lives, personal data collection creating privacy issue is intrinsic. For example, an intelligent traffic management app that updates user about traffic congestion will require that location of the user is collected. To meet the security and privacy requirements is a fundamental challenge for smart city system where huge amount of sensitive data processing is involved [1][20][22][25][26][27]. Threats from hackers, intruders, viruses, worms, Trojans etc has immense potential to disrupt the services and bring down the whole system resulting in enormous losses. Extensive security approaches are required to secure sensitive data at levels including collecting, processing, storing and disseminating. Security and privacy are significant not only in making data and services available, but they are also essential in building citizens trust and confidence in using these systems.

\section{Big data Management}

Understandably, huge amount of data will be generated from all smart city systems. To handle various types of data, with varying velocity an efficient big data management system is required. This system has to be reliable and scalable with no downtime. Continuous generation, collection, processing and storage of massive heterogeneous data from countless smart city sensors has its own intrinsic challenges. Nevertheless, big data collected across city is extremely useful and is vital for achieving objective of smart city. For example, GPS sensors installed on vehicles may give valuable information about transport flow but it will generate huge amount of high velocity data.

\section{Cost}

Smart city evidently would require acquiring enormous IT infrastructure. Huge financial investment is to be obtained to put the system in place. Millions of sensors, thousands and thousands of networking equipment and computing devices will be needed to get end to end connectivity. Similarly, requirement of IT professional and consultancies will make up a considerable amount of expense. This investment is not limited to one time only, operational and maintenance cost of such a huge real time system will be much higher. To meet stringent reliability and efficiency requirements more resources will be required leading to higher overheads. For example, in case of smart traffic management system each car has to fitted with a sensors and thousands of road side units must be installed. Such system cannot afford a downtime and must be highly efficient and reliable. In a typical urban city, cost of implementing such a project may be around millions of dollars.

\section{E. Heterogeneous environment and Interoperability}

Smart city architecture is characterized by Heterogeneity of networks, applications, devices, platforms etc. For instance, Vehicular networks may require adhoc networks like VANETs while close range wireless devices may work on zigbee. The legacy applications and their integration with emerging technologies will also be significant challenge.

\section{F. Efficiency, Availability and Scalability}

Critical systems cannot afford downtime and requires very high availability. Challenge of meeting the tough requirements of availability is directly proportional to the size and complexity of the system. Smart city, not only have a huge infrastructure but its size and complexity will be increasing leaps and bounds as it goes operational. Massive amount of data generated across the city will make availability, scalability and efficiency a critical challenge.

To maintain the efficiency of such a gigantic system is obligatory. Performance optimization of each system, proficient planning, efficient utilization of resources and immediate response to queries are few of the key benefits of smart city. For example, it is expected that in the time of crisis different civil departments may communicate almost instantaneously with each other resulting in immediate access to emergency services. Consequently, resources requirements for cities can be calculated and projects can be initiated well before the demand crosses supply.

For example, energy requirements can be calculated via smart grid and government can plan to meet the energy requirements for upcoming years before it goes critical. Smart grid, if put in place, can assist in maximizing the productivity of current resources. Architectural scalability must be an intrinsic characteristic of such a system where data processing, management, analytics requirements may increase by leaps and bounds. Response time and throughput must not be compromised.

\section{G. Social Adaption}

The smart city seems to be an ideal solution to overcome existing and emerging urban population problems. Although, researchers have also identified challenges with reference to inequality, digital divide and changing cultural habits [1]. Social adaption of such a system requires changing social habits of citizens generally and city management people specifically.

\section{H. App development}

Faster development of new and innovative applications will required so that citizens can take maximum advantage of data that is being collected. If application development is limited to city management it is very likely that people will be disappointed by slow application development. For example, one of the key reasons behind Android's success and wide adaption is its play store, its huge app base where countless applications are uploaded every day. 


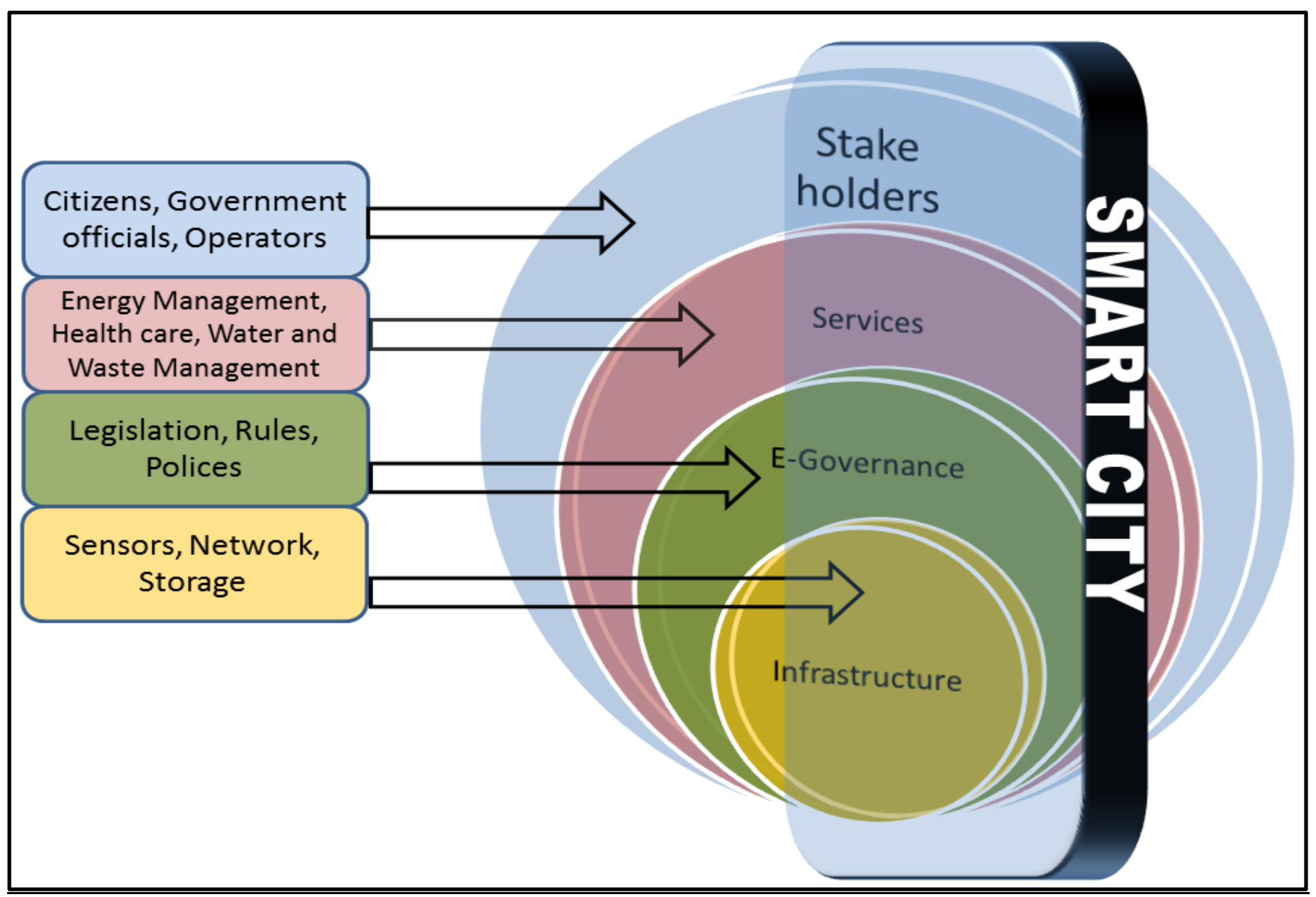

Fig. 1. Smart City Layers

\section{PROPOSED ARCHITECTURE FOR SMART CITY}

Figure 1 shows the key layers of a smart city. ICT infrastructure forms the foundationof a smart city. It is the fundamental layer on which all other components rely. ICT infrastructure comprises high speed wired and wireless network connectivity, high end data centers, physical space enrichment with smart devices, sensors, actuators and much more. E-governance layer facilitates the development of strategic connections between various departments of public sector organization. This layer formulates the policies, rules and legislations to improve the performance of government organizations and offer potential benefits to citizens. Depending upon the infrastructure and policies formulated at e-governance layer, various public services will be offered to citizens and other stake holders, in an efficient and effective manner, ubiquitously.

Traditionally, the city departments have been functioning independently, sharing limited information with other departments in overall city. ICT technologies and infrastructure that are in place in departments only focuses on its on operation. This setup creates lot of chaos and delays the process in implementing or executing a service. Citizens face hardships where information from multiple departments is required. Similarly, in case of disaster, reaction time of departments where mutual communication and coordination is required gets way slower. Resource planning on the basis of real time data is not possible.

This architecture focuses on sharing information not only across departments but also offer data services to other interested parties via open data model. We argue that in smart city, citizens should be provided with cross application services. Using real time data from any number of domains can speed up the reaction/completion time of process improving the overall efficiency of city services. By sharing information, which is the first source of value, the other domains and the city can gain insight and identify impending problems with the intent of responding before these problems occur or escalate. In a smarter city, responses to information and events can be almost instantaneous. Similarly, availability of real time data will lead to efficient resource planning which helps in optimizing resource utilization both at departmental level and overall city level. In a smarter city, city-wide operational processes using data from any number of domains can continuously predict and react to events and trends that are affecting the city.

\section{A. Holistic View}

Figure 2 shows the holistic view of smart city architecture. The approach focuses on managing the city as a system of sub-systems. Each autonomous sub-system is connected to 
Central Data Management System (CDMS), that is fully integrated and interconnected with all sub-systems. All systems share their data with CDMS which in turn can provide cross domain services to citizens. CDMS acts as an integration point for information coming from sub systems. CDMS can use the information and data at its disposal to make better decisions in real time.

\section{B. Zone level architecture}

Each sub system collects data from different zones across the city as shown in Figure 3. Each zone maintains its own data center cloud at site level. For example Water and waste management system will have numerous sites across a city each maintaining its own zone level data. Similarly, Electricity supply and management, Gas management and other public services systems will also have various zonal sites across the city.
Traditionally, city is divided in zones for administration and each zone has its own public service offices. The proposed architecture fits well in such a scenario where each public service and or utility has a zonal representation. Keeping in view, social and technical challenges, it is assumed that smarter city objective will be achieved in an incremental manner. By introducing the concept of zone level service, this architecture supports step by step movement towards a smart city.

Each utility zonal site has its own autonomous system that comprises a local data center, wireless sensor and network infrastructure and technology and facility-related components. A zonal site is an environment that provides processing, storage, networking, management of data within a zone. These zonal sites interact with each other via web services to provide cross zone services to users.

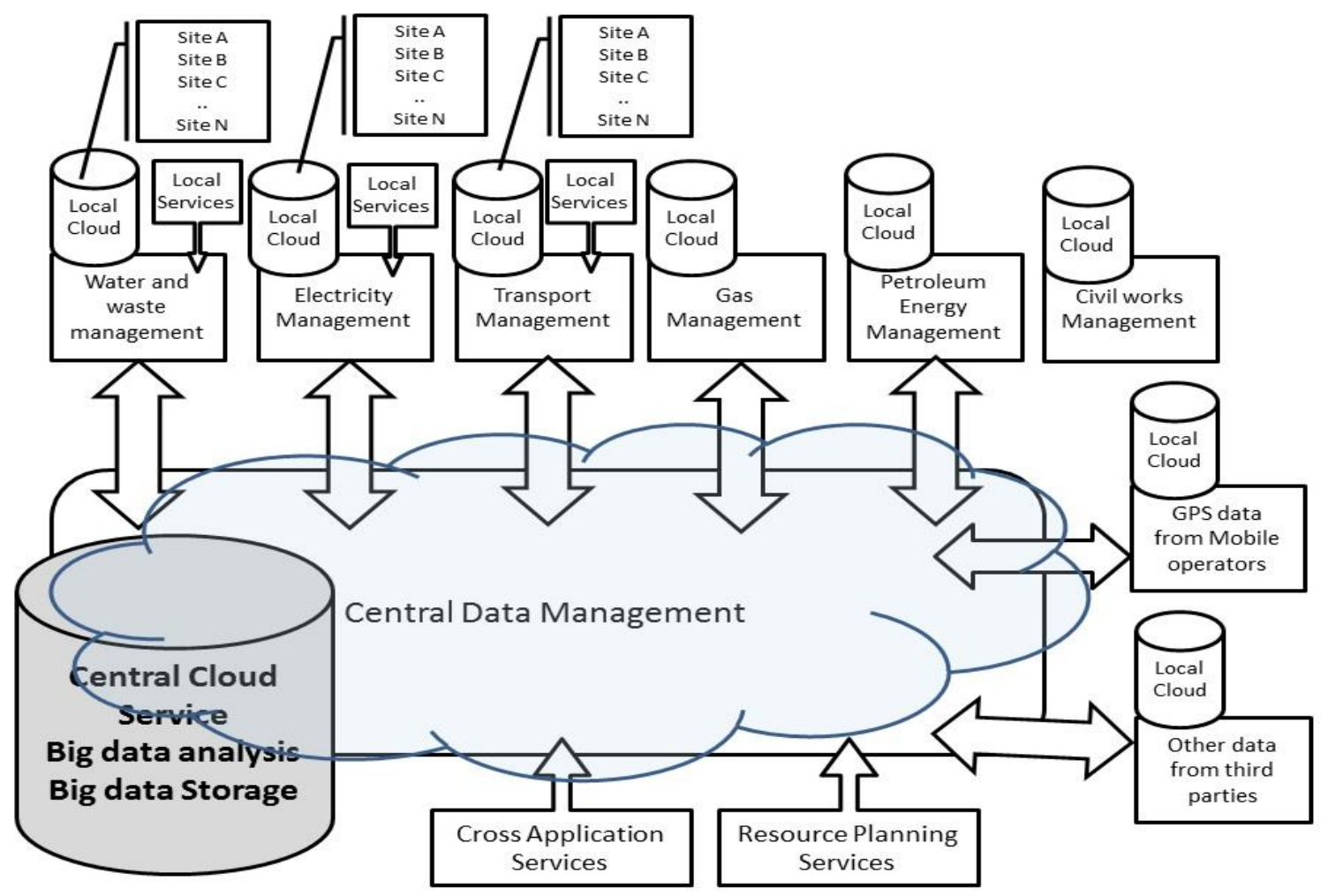

Fig. 2. Holistic view of proposed architecture 


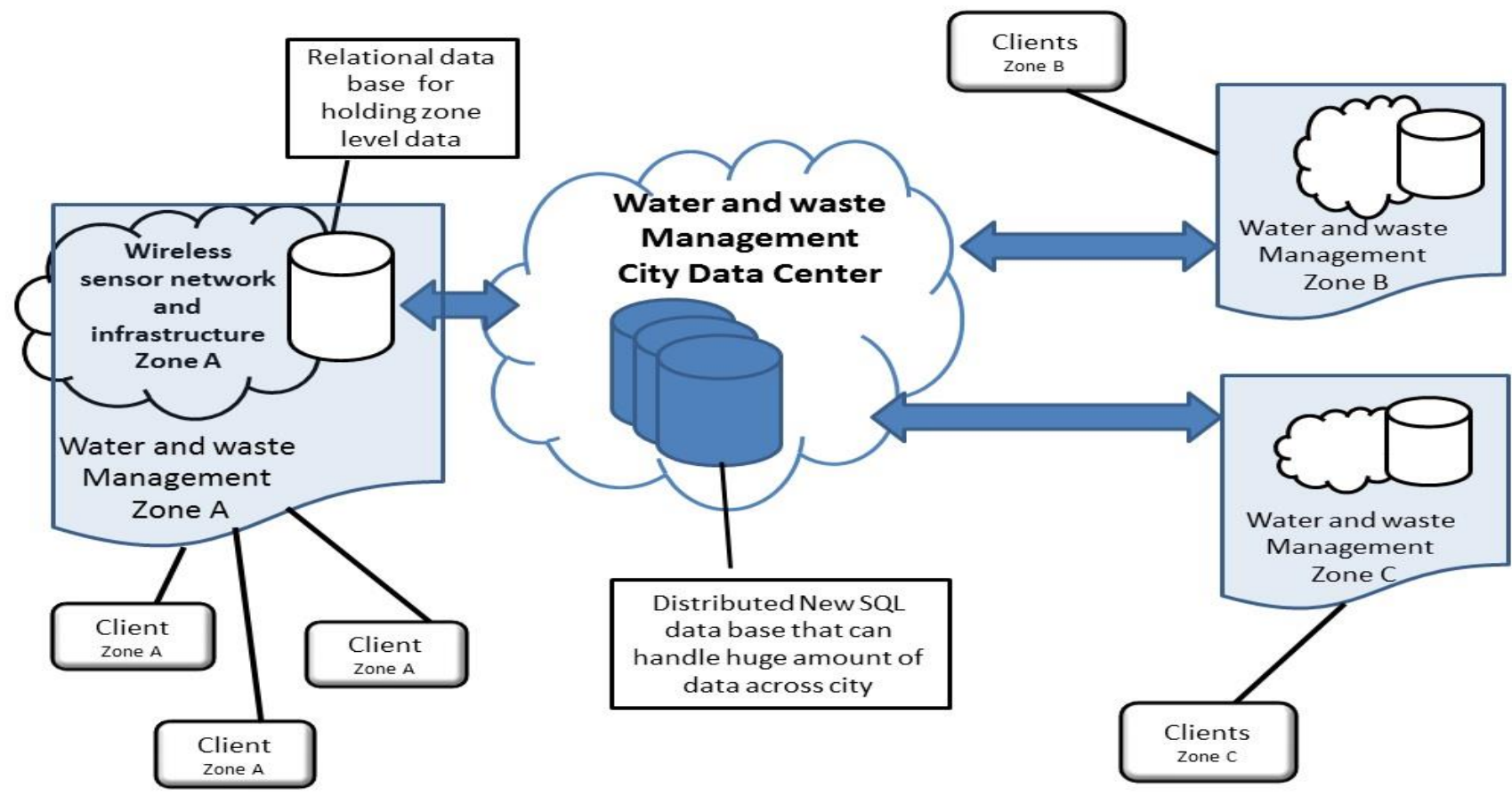

Fig. 3. Zone wise view of proposed architecture

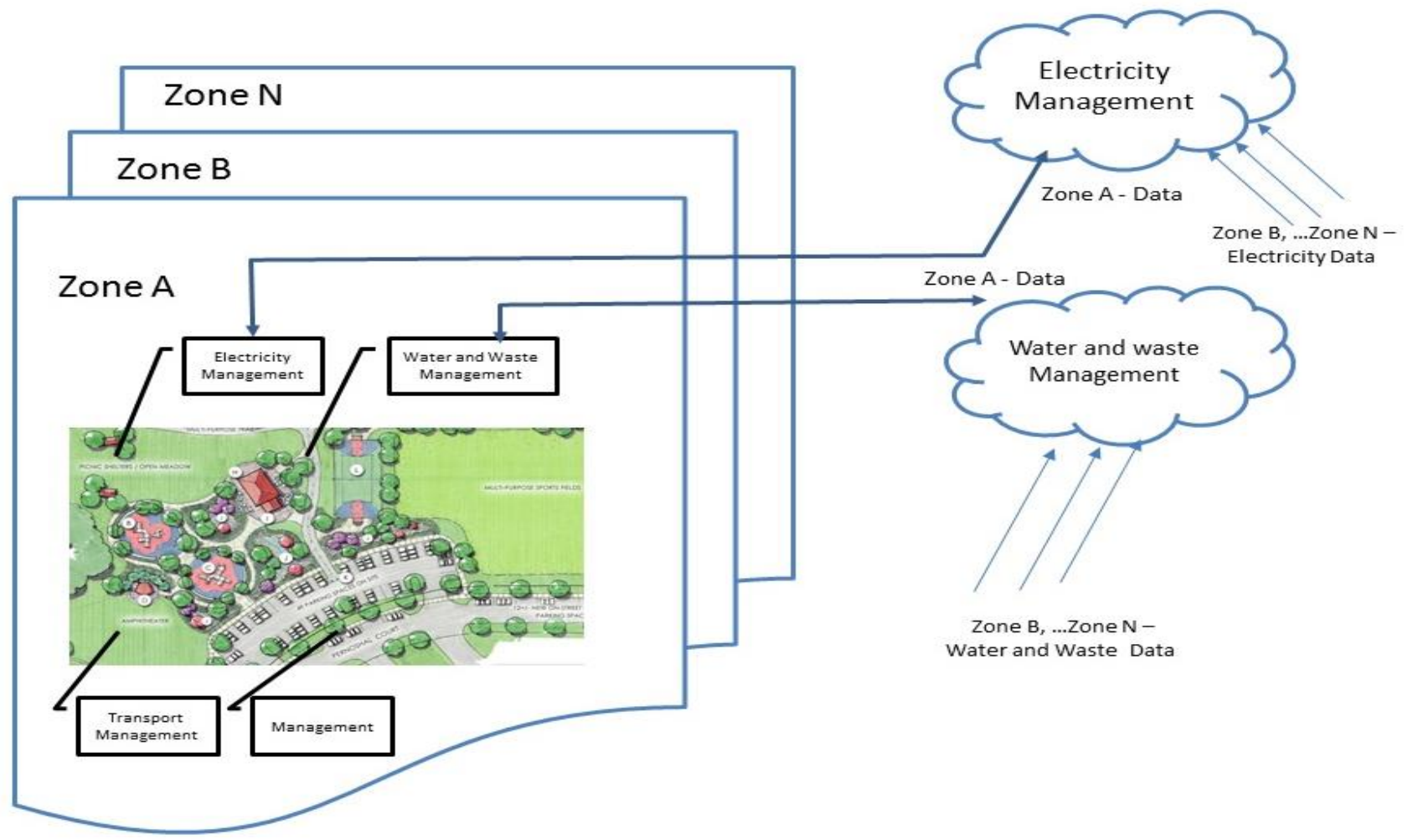

Fig. 4. Data Management at Zonal Sites of Water and Waste Management System. Zone A, Zone B and Zone C are connected to Center of Water and Waste Management System 


\section{Data Management}

Figure 4 depicts water and waste management system for a city. Zone A maintains a local relation database to store data from sensors and other devices in its own region. Clients from Zone A will be receiving services from Zone A datacenter. Relational database is chosen because of its proven ACID(atomic, consistent, isolated, durable) properties. Query optimization may also help in fast processing of user query. All Zonal (Zone A, Zone B, Zone C...Zone N) utility data centers will be connected to main utility data center over reliable high bandwidth connection. Aggregation of data collected from all zonal data centers is stored in distributed New SQL databases like Google Spanner, Nuodb, ClustrixDB. It is assumed that huge data will be generated from all datacenters and its aggregation and center will require big data technologies for management. In order to offer fast and efficient retrieval of data to provide cross zone services New SQL databases are preferred over traditional relational databases and No SQL databases

\section{Service-oriented architecture}

All components of a smart city will be integrated using service oriented architecture. Smart city architecture is essentially a large-scale distributed system which is inherently complex and decentralized. Different platforms, heterogeneous environment and variety of sensors networks will lead to interoperability issues. Service Oriented Architecture with its open standards like XML, WSDL, SOAP, and UDDI not only provides interoperability among diverse platforms but also supports modular design, software reuse, interoperation and application integration. Services offered by one utility let say Water and waste management system can be utilized by Disaster Management System which may be entirely different platform.

\section{E. Open data Model}

It is assumed that huge data will be generated at each utility city center. The proposed architecture introduces a novel idea of open data model. Some of the data collected by utility center is made available to researchers and developers via API. Freelance developers, Professional Application developers and third parties will also have opportunities to develop new analytics tools, new services, etc. Revenue can be generated by charging fee or by advertising. Variety of application will be available for citizens. For example, Traffic management system for city will be collecting huge amount of data about vehicle movements and traffic jams. Applications that can predict peak traffic load resulting in traffic jams, or updates about VIP movements that results and road closures, etc. will be handy utility for citizens. Though implementing such a model has stringent privacy and security requirements.

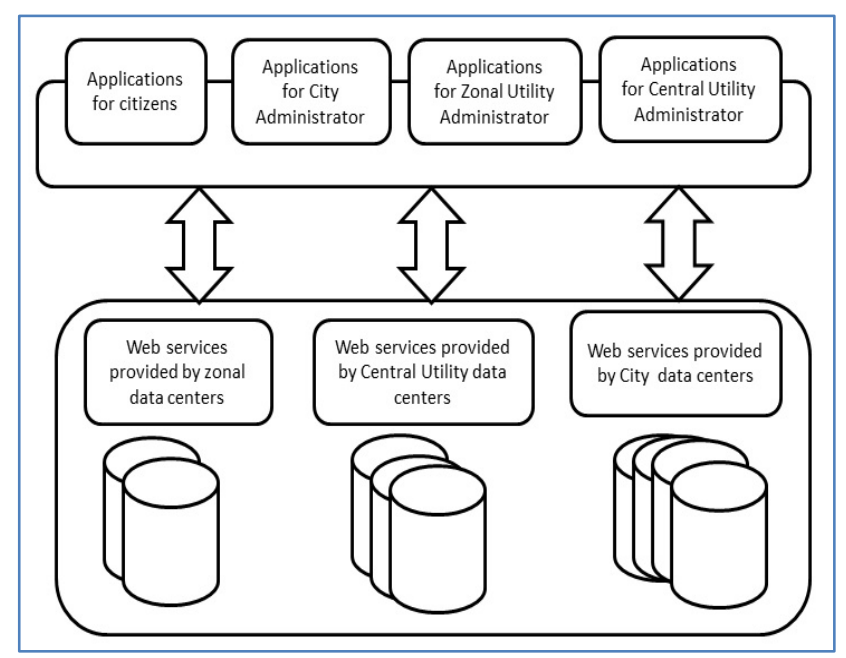

Fig. 5. Service Oriented Architecture

\section{PRoposed Model AND CHALLENGES}

Table 1 lists the key challenges for smart city architecture along with the proposed solution. IT infrastructure and cost challenges include acquiring and laying down enormous network infrastructure (Wired and wireless, bandwidth, connectivity), Smart devices, sensors, kiosks, Wi-Fi hotspots and much more. The proposed model enables Zone wise implementation of each public service which does not require entire infrastructure at once. Nevertheless, this does not bring down the requirement of IT infrastructure but facilitates in moving steadily towards a smarter city. Smart city architecture is characterized by Heterogeneity of networks, applications, devices, platforms etc. The proposed model is based on Service Oriented Architecture. Exposing data services as web services can make information accessible to a wide variety of clients[28]. Architectural scalability and availability must be an intrinsic characteristic of smart city system where data processing, management and analytics requirements may increase by leaps and bounds. These critical systems cannot afford downtime and requires very high availability. The proposed model supports both horizontal and vertical scalability. Horizontal scalability means that more and more public services can be plugged in easily. Zone wise implementation of each public service provides vertical scalability ensuring Quality of Service(QoS) at zone level. Security and privacy are inherent challenges; the proposed model recommends exposing data as web service.WS-Security is particularly useful because it provides encryption-based, message-level security data[29][30]. In the proposed model, each public service is running its own data center at zone level. 


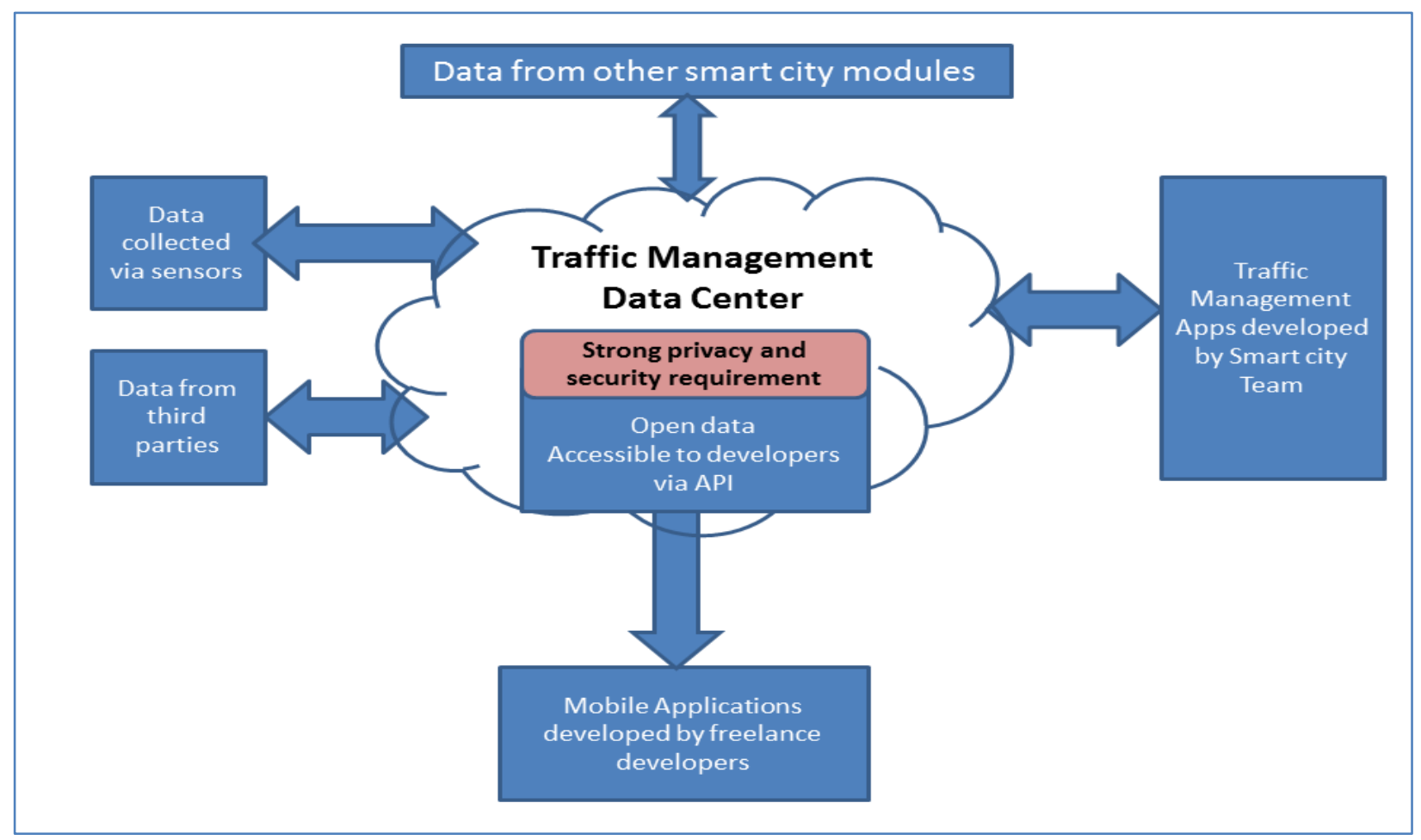

Fig. 6. Exposing data via API

However, they exchange information in real-time but the system itself is not controlled centrally. Attacks on one utility's zonal data center cannot bring down the whole system. Besides, redundancy for replication and efficiency is inherent in cloud based systems. This model also proposes that the anonymized data is exposed via web services, with the consent of user to ensure privacy. Nevertheless, personal data collected will be for greater good. According to McKinsey[31] , applying personal location data has the potential to provide more than $\$ 800$ billion in economic value to individual consumers and organizations over the next decade.Efficiency is critical for the success and adaption of smart city system. Citizens will expect to get their problems resolved more efficiently. For e.g. more immediate access to emergency services, cities become more resilient in times of crisis. Similarly, efficient planning and utilization of resources is presumed. The proposed model include cross domain services that can process queries from multiple domains in real time. Various departments can co-ordinate and cooperate instantly and share their data via web services. Resource planning at central data management system (CDMS), and at each utility center results in efficient planning and utilization of resources as real data is available for analysis. Furthermore, hierarchical cloud model assists in efficiently handling big data that is continuously generated from heterogeneous sources. 


\begin{tabular}{|c|c|c|}
\hline & Challenge & Proposed model \\
\hline 1 & IT Infrastructure & $\begin{array}{l}\text { Zonal Sites of each public utility } \\
\text { Zone wise implementation of each public service does not require all the infrastructure at once. The proposed } \\
\text { model streamlines step-wise implementation of smart city. Nevertheless, this does not brings down the } \\
\text { requirement of IT infrastructure but facilitates in moving steadily towards a smarter city. }\end{array}$ \\
\hline 2 & Cost & $\begin{array}{l}\text { Zonal Sites of each public utility } \\
\text { Zone wise implementation of each service may not require huge investment at once. In a long run, use of the ICT } \\
\text { to deliver public services will reform the speed and effectiveness of public service delivery and administration, } \\
\text { in turn, providing improved service delivery, Reduced consumer costs and Social benefits [32]. }\end{array}$ \\
\hline 3 & $\begin{array}{l}\text { Heterogeneous environment } \\
\text { /Interoperability }\end{array}$ & $\begin{array}{l}\text { Service Oriented Architecture. } \\
\text { The proposed model is based on Service Oriented Architecture. } \\
\text { Exposing data services as web services can make data service information accessible to a wide variety of client. } \\
\text { Web services makes it possible for systems to integrate with each other independent of underlying platform. }\end{array}$ \\
\hline 4 & Availability and Scalability & $\begin{array}{l}\text { Zonal Sites of each public utility } \\
\text { The proposed model supports both horizontal and vertical scalability. Horizontal scalability means that more and } \\
\text { more public services can be plugged in easily. } \\
\text { Zone wise implementation of each public service provides vertical scalability ensuring Quality of Service(QoS) } \\
\text { at zone level. } \\
\text { Hierarchical cloud model, basically a cloud model, is characterized by high availability and scalability } \\
\text { inherently. Furthermore, each zone can enhance its resources, as and when required, to ensure } 24 / 7 \text { availability } \\
\text { to its users. }\end{array}$ \\
\hline 5 & Security & $\begin{array}{l}\text { Service Oriented Architecture - Using Web Services } \\
\text { The proposed model recommends exposing data as web service. } \\
\text { WS-Security is particularly useful because it provides encryption-based, message-level security data }\end{array}$ \\
\hline 6 & Privacy & $\begin{array}{l}\text { Service Oriented Architecture - Using Web Services } \\
\text { The proposed model defines user as the owner of data. However, policies and rules can be defined by the e- } \\
\text { governance layer. Data is only provided to known an authentic party. It is recommended that anonymized data } \\
\text { is exposed via web services after the consent of user. }\end{array}$ \\
\hline 7 & Efficiency & $\begin{array}{l}\text { Hierarchical Cloud Model } \\
\text { As data zone level queries will be entertained by zonal data center, the proposed model is expected to perform } \\
\text { better. } \\
\text { The cross domain services can process queries from multiple domains in real time. Various departments can co- } \\
\text { ordinate and cooperate instantly and share their data via web services. Resource planning at central data } \\
\text { management system (CDMS), and at each utility center results in efficient planning and utilization of resources } \\
\text { as real data is available for analysis. }\end{array}$ \\
\hline 8 & Big data Management & $\begin{array}{l}\text { Hierarchical Cloud Model } \\
\text { Zonal Sites of each public utility } \\
\text { Zone wise distribution of data helps in storing and analyzing data efficiently. For example, city transport system } \\
\text { will have zonal data centers across city. The data generated from each zone will be collected, stored and } \\
\text { analyzed at zone level. Nonetheless, aggregated data of each zone will be sent to main city transport system. } \\
\text { This division, helps in efficient management of big data. }\end{array}$ \\
\hline 9 & $\begin{array}{l}\text { Social Adaption and app } \\
\text { development }\end{array}$ & Open data model - Smart city App store \\
\hline
\end{tabular}

\section{CONCLUSION}

The paper presents a four layer view of a smart city. Requirements and challenges in realizing a smart city are presented. Hierarchical data management architecture is proposed that facilitates distributed data management at zone level enhancing efficiency, availability and scalability of services. Service oriented nature of the proposed architecture conforms to the heterogeneous environment of smart city. The Open data model for smart city will give way to researchers and free-lance programmers to contribute to smart city app development leading to smart city app store. E-governance layer is also one of the fundamental layers of smart city but this research deals mostly with the technicalities of smart city architecture. The socio-techno challenges like accessibility, digital divide, Adaptability etc. are not addressed by the proposed model.

\section{REFERENCES}

[1] H. Chourabi, T. Nam, S. Walker, J. R. Gil-Garcia, S. Mellouli, K. Nahon, T. a. Pardo, and H. J. Scholl, "Understanding Smart Cities: An Integrative Framework," 2012 45th Hawaii Int. Conf. Syst. Sci., pp. 2289-2297, Jan. 2012.

[2] R. Giffinger and N. Pichler-Milanović, "Smart cities: Ranking of European medium-sized cities," 2007.

[3] R. Giffinger, R., Fertner, C., Kramar, H., Kalasek and E. PichlerMilanović, N., \& Meijers, "Smart cities Ranking of European mediumsized cities," Vienna, Austria Cent. Reg. Sci. (SRF), Vienna Univ. Technol., 2007.

[4] Bowerman, B., et al. "The vision of a smart city." 2nd International Life Extension Technology Workshop, Paris. 2000.

[5] Harrison, Colin, et al. "Foundations for smarter cities." IBM Journal of Research and Development 54.4 (2010): 1-16..

[6] Moss Kanter, Rosabeth, and Stanley S. Litow. "Informed and interconnected: A manifesto for smarter cities." Harvard Business School General Management Unit Working Paper 09-141 (2009). 
[7] Alawadhi, Suha, et al. "Building understanding of smart city initiatives." Electronic Government. Springer Berlin Heidelberg, 2012. 40-53.

[8] Marceau, Jane. "Introduction: Innovation in the city and innovative cities." Innovation: Management, Policy \& Practice 10.2-3 (2008): 136145.

[9] D. Washburn, U. Sindhu, S. Balaouras, R. A. Dines, N. M. Hayes, and L. E. Nelson, "Helping CIOs Understand ' Smart City ' Initiatives," 2010.

[10] R. Hollands, "Will the real smart city please stand up? Intelligent, progressive or entrepreneurial?," City, 2008.

[11] Bakıcı, Tuba, Esteve Almirall, and Jonathan Wareham. "A smart city initiative: the case of Barcelona." Journal of the Knowledge Economy 4.2 (2013): 135-148.

[12] Caragliu, Andrea, Chiara Del Bo, and Peter Nijkamp. "Smart cities in Europe." Journal of urban technology 18.2 (2011): 65-82.

[13] L. Hopkins and P. K. Isom, "Front cover Smarter Cities Series: Understanding the IBM Approach to Efficient Buildings."

[14] Kehoe, Mike, et al. "Smarter cities series: A foundation for understanding IBM smarter cities." Redguides for Business Leaders, IBM (2011).

[15] Al-Hader, Mahmoud, et al. "Smart city components architicture." Computational Intelligence, Modelling and Simulation, 2009. CSSim'09. International Conference on. IEEE, 2009.

[16] P. Research, "Smart Cities. Intelligent Information and Communications Technology Infrastructure in the Government, Buildings, Transport, and Utility Domains,” 2011. [Online]. Available: http://www.navigantresearch.com/.

[17] G. Piro, I. Cianci, L. A. Grieco, G. Boggia, and P. Camarda, "Information Centric Services in Smart Cities."

[18] Anthopoulos, Leo G., and Ioannis A. Tsoukalas. "The implementation model of a Digital City. The case study of the Digital City of Trikala, Greece: e-Trikala." Journal of e-Government 2.2 (2006): 91-109.

[19] Daniel, Sylvie, and Marie-Andree Doran. "geoSmartCity: geomatics contribution to the smart city." Proceedings of the 14th Annual International Conference on Digital Government Research. ACM, 2013.

[20] P. Suresh, "Understanding Challenges in e-Governance," Better Account. with e-governance, pp. 61-63, 2011.

[21] Dillon, J., and W. Pelgrin. "E-government/commerce in New York State." Office of Technology, New York, NY (2002)..

[22] Alghamdi, Ibrahim A., Robert Goodwin, and Giselle Rampersad. "Egovernment readiness assessment for government organizations in developing countries." Computer and Information Science 4.3 (2011): p3..

[23] Giffinger, Rudolf, et al. Smart cities-Ranking of European mediumsized cities. Vienna University of Technology, 2007.
[24] Vasseur, Jean-Philippe, and Adam Dunkels. Interconnecting smart objects with ip: The next internet. Morgan Kaufmann, 2010..

[25] Wan, Jiafu, et al. "From machine-to-machine communications towards cyber-physical systems." Computer Science and Information Systems 10.3 (2013): 1105-1128.

[26] Sanchez, Aurora, et al. "The relationship between IT for communication and e-government barriers." AMCIS 2003 Proceedings (2003): 104.

[27] Laplante, Phillip A. "Who's Afraid of Big Data?." IT Professional 15.5 (2013): 6-7.

[28] Hamad, Hatem, Motaz Saad, and Ramzi Abed. "Performance Evaluation of RESTful Web Services for Mobile Devices." Int. Arab J. e-Technol. 1.3 (2010): 72-78.

[29] Yuan, Eric, and Jin Tong. "Attributed based access control (ABAC) for web services." Web Services, 2005. ICWS 2005. Proceedings. 2005 IEEE International Conference on. IEEE, 2005.

[30] Atkinson, Bob, et al. "Web services security (WS-Security)." Specification, Microsoft Corporation (2002).

[31] Manyika, James, et al. "Big data: The next frontier for innovation, competition, and productivity." (2011).

[32] G. Bonham, J. Seifert, and S. Thorson, "The transformational potential of e-government: the role of political leadership," 4th Pan Eur. Int. Relations Conf. Univ. Kent, 2001.

[33] Hannola, Lea, and Päivi Ovaska. "CHALLENGING FRONT-END-OFINNOVATION IN INFORMATION SYSTEMS." Journal of Computer Information Systems 52.1 (2011).

[34] Barba, Carolina Tripp, et al. "Smart city for VANETs using warning messages, traffic statistics and intelligent traffic lights." Intelligent Vehicles Symposium (IV), 2012 IEEE. IEEE, 2012.

[35] Khazanchi, Deepak. "Information technology (IT) appropriateness: the contingency theory of 'fit' and IT implementation in small and medium enterprises." Journal of Computer Information Systems 45.3 (2005): 8895.

[36] Chen, Kuanchin, and Alan I. Rea. "Protecting personal information online: A survey of user privacy concerns and control techniques." Journal of Computer Information Systems 44.4 (2004): 85-92.

[37] Shelton, Taylor, Matthew Zook, and Alan Wiig. "The 'actually existing smart city'." Cambridge Journal of Regions, Economy and Society 8.1 (2015): 13-25.

[38] Ricciardi, Francesca, and Stefano Za. "Smart City Research as an Interdisciplinary Crossroads: A Challenge for Management and Organization Studies." From Information to Smart Society. Springer International Publishing, 2015. 163-171.

[39] Kitchin, Rob. "The real-time city? Big data and smart urbanism." GeoJournal79.1 (2014): 1-14.

[40] Sanchez, Luis, et al. "SmartSantander: IoT experimentation over a smart city testbed." Computer Networks 61 (2014): 217-238. 